\title{
La estudiosidad como principio fundante del carisma dominicano, en función del anuncio del evangelio
}

\section{Sor Leonor Camaro Carvajal O.P \\ Rectora Colegio de Nuestra Señora del Rosario \\ Manizales}

La razón fundamental por la cual La Congregación de Hermanas Dominicas de Santa Catalina de Siena, lidera un proceso permanente e integral de formación orientado al acompañamiento pedagógico de la juventud, desde el servicio y proyección social de Obras e Instituciones educativas, si bien es cierto que esta referida a la búsqueda de la excelencia y la calidad educativa en el país, busca ante todo y de manera prioritaria dar cumplimiento a la misma razón de ser de la Orden de Predicadores de Santo Domingo de Guzmán, expresada en el anuncio del evangelio y en la búsqueda de la VERDAD; de modo que se contribuya a través del ministerio de la enseñanza y de acciones concretas en la noble misión de evangelizar a la juventud y a la familia colombiana, mediante la educación como pretexto para anunciar la palabra del Evangelio.

Al decir de Fray José Antonio Solórzano. O.P, "Toda familia religiosa dentro de la Iglesia se ha formado con unos ideales de futuro, con un deseo de servicio y vivencia del Evangelio según las visiones peculiares de sus fundadores y según las circunstancias históricas que requerían un determinado y concreto servicio a los hombres y a Dios...Un Dominico que busque creatividad en su apostolado, riesgos en el pensar y actuar, zonas fronterizas en su investigación, un dominico que arriesgue su vida, su fe, que esté siempre en sintonía con su tiempo, que se deje interpelar por el nuevo mundo en gestación y se coloque en actitud siempre atenta de futuro...será un dominico fiel al espíritu de Domingo de Guzmán y a la expansión del Reino de Dios "`.... a través de la PREDICACIÓN.

1 En el texto: «Dominicos un Paisaje interior..., para tiempos democráticos». Testimonium Veritatis. N. 4. Bucaramanga. 2000. Pág. 54
El desarrollo de un proceso educativo, en el marco de las Obras de la Congregación, si bien es cierto que atiende a las características y particularidades propias de cada contexto cultural, histórico y geográfico en el que esta situada la Institución educativa, implica el reconocimiento y puesta en practica de fundamentos esenciales para la formación de la nueva juventud, dados por el Padre Fundador Fray Saturnino Gutiérrez O.P. En la perspectiva de la pedagogía Saturniniana, cada Obra educativa independiente del enfoque pedagógico que direccione la dinámica Institucional, ha de fortalecer la formación ciudadana desde los más genuinos sentimientos de fraternidad, y amor por la patria. Su propuesta de educación, iluminadora, y visionaria de acuerdo con los signos de los tiempos, pone de manifiesto la relevancia de una educación integral de calidad, que privilegiará el dominio de valores humano cristianos concretos $^{2}$, para formar individuos competentes para ser ciudadanos del mundo, pero profundamente comprometidos con su identidad de patria.

El desafío de una educación pertinente con los adelantos y cambios permanentes propios de épocas como la modernidad y la post modernidad, implica la preparación de docentes competentes y capacitados para ser líderes y gestores en el contexto de la relación pedagógica, del resurgimiento espiritual $^{3}$ necesario para garantizar y favorecer la formación integral de las estudiantes, la defensa de la vida en todas sus manifestaciones, y la vivencia del evangelio como opción de autorrealización, y como oportunidad de construcción de una nueva sociedad, en la que se favorezca el bien común. Dicho proceso de

2 Hechos vida a través del PARADIGMA PEDAGÓGICO ROSARISTA, y contenidos en los siete principios educativos.

3 En la perspectiva de la UNESCO, de acuerdo con los planteamientos de Jacques Delors en su texto: «La educación encierra un tesoro", una de las tensiones que han de superarse a través de la educación, esta implícita en la lucha entre una sociedad hedonista, y la necesidad de un resurgimiento, o redescubrimiento de los valores trascendentes en el individuo.

FACULTAD DE FDUCACIÓN ・ 13 
formación docente sin descuidar los campos de actualización en las áreas de formación pedagógica, disciplinar, neuropsicopedagógica, e investigativa, ha de estar orientada de manera especial, al fortalecimiento de una docencia en pastoral que articule los fundamentos de la Pedagogía Dominicana, y Saturniniana con los más recientes desarrollos y avances en el campo de la educación.

Para los Dominicos la estudiosidad se constituye en un elemento esencial del Carisma, el cual le permite a la Congregación ser coherente con los desafíos y los signos de los tiempos. Al respecto se señala que en la historia de los Dominicos:

«Ha primado un cierto cultivo en hondura de las ciencias Teológicas, filosóficas, o de otros ordenes como un deseo de mayor conocimiento de Dios, del mundo y de los hombres a la luz de la razón, en esa difícil conjunción FE- RAZON.

Hay preocupación por las facetas intelectuales, deseo de conocer, de no quedarse en planteamientos sencillos; existe inquietud por calar en la esencia de las cosas y de los seres, hay vocación por el saber, la ciencia y la sabiduría» ${ }^{4}$

En coherencia con esta vocación de estudiosidad y de predicación, que orienta la Obra Educativa de los Colegios de la Congregación, se presenta esta selección de artículos elaborada por los docentes del Colegio de Nuestra Señora del Rosario de la ciudad de Manizales, a partir de la experiencia de formación adelantada bajo la modalidad de Diplomado con la Universidad de Manizales, así como las diversas ponencias presentadas por los docentes de Universidad y de los diferentes colectivos de área de la Institución. La producción intelectual adelantada durante los años del 2002 y 2003, da cuenta de la articulación, y aprehensión que los docentes del colegio han venido elaborando, en torno a la articulación entre Pedagogía Tomasina, Pedagogía Saturniniana, Teoría de las inteligencias múltiples, Enseñanza para la comprensión y desarrollo de competencias.

Desde la búsqueda constante de conocimiento, y desde el ideal de consolidar un proceso educati- vo de base meta cognitiva, centrado en la formación humano cristiana que apunte a la excelencia, la Institución asume la reflexión en torno a la PRAXIS PEDAGÓGICA, como oportunidad permanente para que Directivos y docentes, puedan aportar elementos de reflexión pedagógica, en el proceso de consolidación de la pedagogía como ciencia de la educación desde un Carisma propio. Es por esto, que se espera que los artículos que aquí se comparten a través de la Revista «Plumilla» de la Universidad de Manizales, y que dan cuenta del esfuerzo conjunto de dos Instituciones en función de la calidad de la educación en la región y en el país, sirvan como inspiración para que muchos otros Colegios del Rosario y de CONACED, se sumen al esfuerzo de construir Comunidad Académica e investigativa.

Como Rectora actual del Colegio de Nuestra Señora del Rosario de Manizales, agradezco a todas las hermanas que desde su paso por la Institución, han contribuido de alguna forma en la consolidación de este sueño escritural que aquí se presenta, a través de la publicación de la revista «PLUMILLA EDUCATIVA» en su edición n. 3. Agradezco la participación gerencial y el acompañamiento pedagógico que cada una de las hermanas integrantes de la Comunidad y de las Rectoras que me precedieron por el aporte que han brindando en la consolidación de la calidad educativa de esta Institución, y dejo en consideración de usted querido lector, el resultado del esfuerzo reflexivo e investigativo de la Comunidad Educativa liderado durante los últimos años de gestión y búsqueda de calidad.

Agradecimientos sinceros a todos los miembros de la Universidad de Manizales, y de manera prioritaria a todos los integrantes de la Facultad de Educación, así como a todos los directivos y docentes que aún están en el Colegio y a los que ya se han ido, por sus invaluables aportes a la construcción del conocimiento pedagógico desde el Carisma de Fray Saturnino Gutiérrez. O.P.

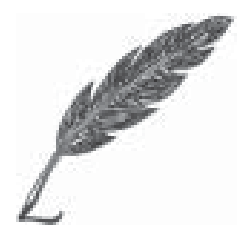

4 Ibíd. Pág. 69. 